\title{
Mutation in the zonadhesin-like domain of $\alpha$-tectorin associated with autosomal dominant non-syndromic hearing loss
}

\author{
Nicole A lloisio ${ }^{1}$, L aurette M orlé ${ }^{1}$, M uriel Bozon ${ }^{1}$, Jacqueline G odet ${ }^{1}, \mathrm{~K}$ ristien \\ Verhoeven ${ }^{2}$, G uy Van Camp ${ }^{2}$, Henri Plauchu ${ }^{3}$, Philippe M uller ${ }^{4}$, Lionel Collet ${ }^{5}$ and \\ G eneviève Lina-Granade ${ }^{5}$ \\ ${ }^{1}$ Centre de G énétique M oléculaire et Cellulaire, CNRS U M R 5534, U niversité Claude Bernard-L yon I, Villeurbanne, \\ France \\ ${ }^{2} D$ epartment of M edical G enetics, U niversity of A ntwerp, A ntwerp, B elgium \\ ${ }^{3}$ Service de G énétique, H ospices Civils de L yon, H ôtel-D ieu, Lyon \\ ${ }^{4}$ Service d'ORL, Centre H ospitalier, R omans sur I sère \\ ${ }^{5} \mathrm{~L}$ aboratoire N eurosciences et Systèmes Sensoriels, D épartement CNRS U PRE SA 5020, d'O to-R hino-L aryngologie, \\ H ôpital E douard Herriot, Lyon, France
}

A gene responsible for autosomal dominant non-syndromic hearing impairment in two families (D FNA 8 and D FNA 12) has recently been identified as TE CTA encoding $\alpha$-tectorin, a major component of the tectorial membrane. In these families, missense mutations within the zona pellucida domain of $\alpha$-tectorin were associated with stable severe mid-frequency hearing loss. The present study reports linkage to D FNA 12 in a new family with autosomal dominant high frequency hearing loss progressing from mild to moderate severity. The candidate region refined to $3.8 \mathrm{cM}$ still contained the TECTA gene. A missense mutation (C 1619S) was identified in the zonadhesin-like domain. This mutation abolishes the first of the vicinal cysteines $\left({ }^{1619} \mathrm{C}\right.$ ys- G ly-Leu- $\left.{ }^{1622} \mathrm{Cys}\right)$ present in the D 4 von Willebrand factor (vW f) type $D$ repeat. These results further support the involvement of TECTA mutations in autosomal dominant hearing impairment, and suggest that vicinal cysteines are involved in tectorial membrane matrix assembly.

Keywords: hereditary deafness; hearing impairment; ear; cochlea; tectorial membrane; tectorin; vicinal cysteines; linkage analysis

Inherited non-syndromic hearing impairment constitutes about half the sensorineural hearing defect cases

Correspondence: $\mathrm{N}$ Alloisio PhD, Génétique Humaine, CNR S U M R 5534, C G M C, B âtiment 741, U niversité Lyon I, 43, boulevard du 11 Novembre 1918, 69622 Villeurbanne Cedex, France. Tel: 33472446260 ; Fax: 33472440555 ; E-mail: alloisio@univ-lyon1.fr

R eceived 13 July 1998; revised 21 September 1998; accepted 25 September 1998 in children. ${ }^{1,2}$ To date, 19 dominant (DFNA 1 to 19), 20 recessive (DFNB 1 to 20 ) and $8 X$-linked (DFN 1 to 8 ) loci have been reported. ${ }^{3}$ O nly eleven genes have so far been identified. ${ }^{3}$ The DFNA 12 locus was previously mapped to a $36 \mathrm{cM}$ interval on chromosome 11q22-24 in a Belgian family. ${ }^{4}$ The DFNA 8 locus was assigned to chromosome $11 \mathrm{q}$ in an A ustrian family. ${ }^{3}$ R ecently, the gene encoding $\alpha$-tectorin (TECTA) was mapped within the above genetic interval. ${ }^{5} \mathrm{M}$ issense mutations within the zona pellucida domain of $\alpha$-tectorin were identified 


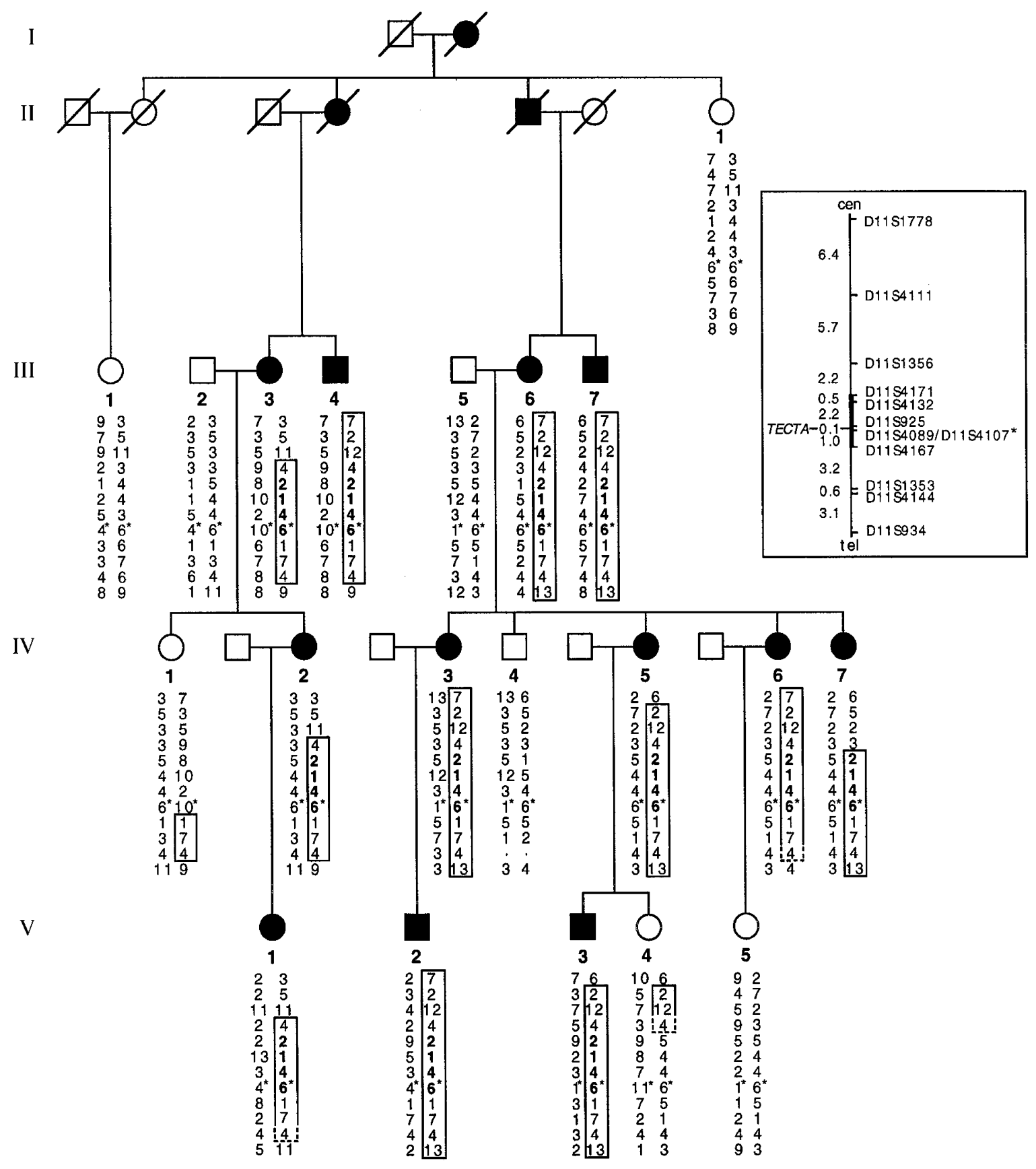

Figure 1 Pedigree of the French family, showing haplotypes of chromosome 11 markers. Filled symbols denote affected individuals. O nly family members included in the linkage study are numbered. The D F N A 12-linked haplotype is boxed. D ashed lines indicate that the genotype is uninformative for those markers. B old numbers indicate non-recombinant marker genotypes. Insert: G enetic distances (cM ) between markers; ${ }^{13}$ bold line: the $3.8 \mathrm{cM}$ refined interval. L ocation of TE CTA is indicated.

in both these families. ${ }^{6}$ The tectorial membrane, an extracellular matrix of the cochlea, plays a crucial role in the transmission of sound to the sensory hair cells. $\alpha$ and $\beta$-tectorins interact with each other to form the filament-based non-collagenous matrix. A $n$ alteration of $\alpha$-tectorin is likely to disrupt the structure of this matrix and, in consequence, to lead to inefficient transmission of sound.

The present French family (Figure 1) displayed autosomal dominant hearing impairment. In most of the 12 
patients, hearing impairment was bilateral, symmetrical, cochlear, mild to moderate and predominating on high frequencies. It was detected before the age of 6 by subjective play-conditioned audiometry and transiently-evoked otoacoustic emission recording, performed as previously described. ${ }^{7} \mathrm{H}$ istories of delayed speech development suggested a prelingual onset in several patients. Linear regression analysis, based on all available audiograms from the 12 patients, showed a $0.7 \mathrm{~dB} /$ year age-linked progression of the $0.5-4 \mathrm{kHz}$ average hearing loss. A bilateral vestibular dysfunction was suggested in patients IV.3, IV.5 and V2, who had started walking only at 24 months. Other patients' walking age was not known; none had any history of vertigo or dizziness.

Linkage analysis to known deafness loci ${ }^{3}$ revealed a positive two-point lod score of 4.71 (at $\theta=0$ ) for DFNA 12 with marker D 11S925, confirmed by additional markers (Figure 1). Combining information from nine recombinants, the candidate region was reduced to a $3.8 \mathrm{cM}$ interval, still containing the TECTA gene. The presence of the known TECTA mutations was ruled out using specific restriction enzyme digestions. ${ }^{6} \mathrm{~A}$ new mutation within the zona pellucida domain was also excluded by direct sequencing of exons 17 to 20 . Singlestrand conformation polymorphism screening of the 19 remaining exons was then conducted, as previously described. $^{3,6}$ Exon 14 analysis revealed additional bands in patients. Its direct sequencing identified a heterozygous $\mathrm{G}$ - > C missense mutation at nucleotide 4857 (Figure 2), which replaces the cysteine at residue 1619 with a serine (C1619S) and creates a new site for $\mathrm{Mspl}$. The C1619S mutation segregated in the 12 affected members and was not in any of the 8 unaffected members or in 100 French controls. No other variation was found in patients except for a silent mutation (4099G->A; T1366T) in exon 11 which turned out to be a frequent polymorphism ( 9 out of 25 French controls were found to be heterozygotes).

The $\mathrm{C} 1619 \mathrm{~S}$ amino acid change abolishes the first of the vicinal cysteines $\left({ }^{1619} \mathrm{CG} \mathrm{L} \mathrm{L}^{1622} \mathrm{C}\right)$ present in the $\mathrm{D} 4$ $v W f$ type $D$ repeat of the zonadhesin-like domain., ${ }^{6,8}$ Cysteine residues separated by two amino acids correspond to the catalytic site of protein disulphide isomerases. ${ }^{9}$ The CGLC motif present in the $D 1$ and D 2 repeats of $\mathrm{vWf}$ has been shown to catalyse disulphidebonded oligomerisation of $\mathrm{vWf}^{10}$ This motif is also found in $D$ repeats of zonadhesin and intestinal mucin MUC2, which both exist as covalent oligomers. ${ }^{11,12}$ Therefore the CGLC motif present in the D 1 and D 4

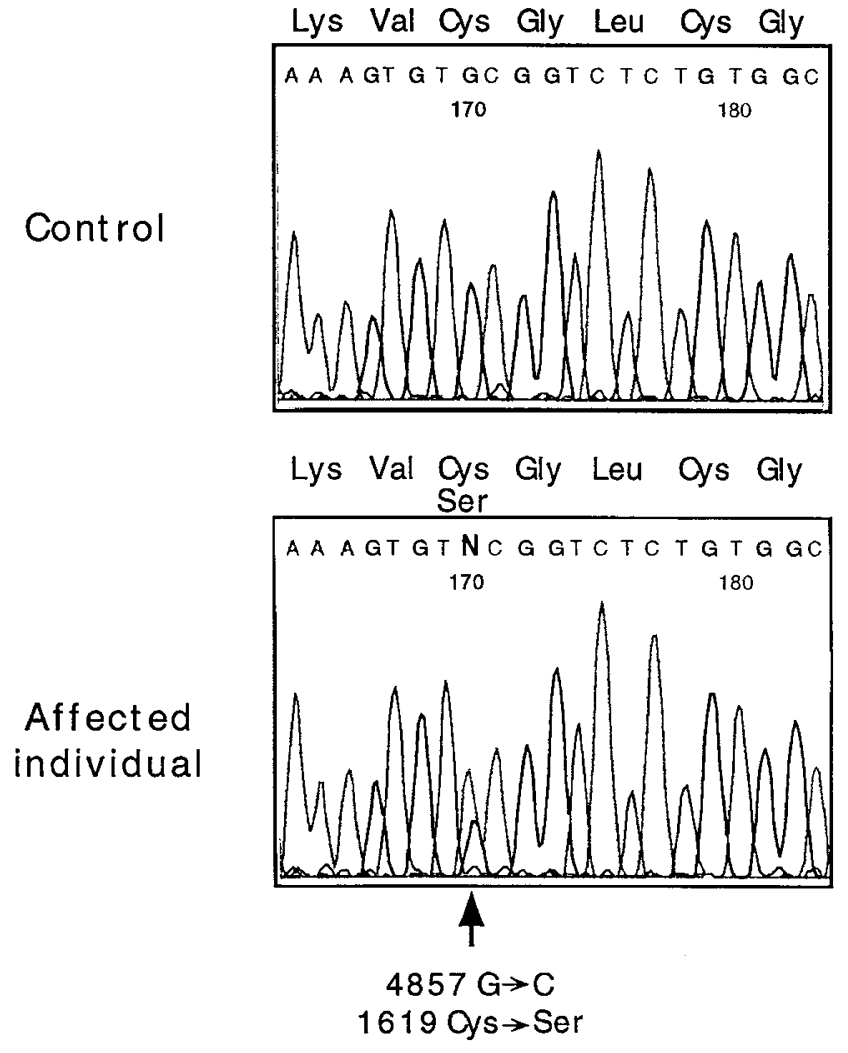

Figure 2 DNA sequences showing the TECTA missense mutation in the French family. Exon 14 PCR-products were sequenced on an Applied Biosystems (ABI373) DNA sequencer.

repeats of $\alpha$-tectorin may be involved in some aspect of tectorial membrane matrix assembly. ${ }^{6,8}$ However, at present, the respective roles which the three distinct domains composing $\alpha$-tectorin may play in organising this filament-based matrix in conjunction with $\beta$-tectorin remain to be elucidated, and the effect of the C 16195 substitution needs to be investigated.

This French family presented a progressive mild to moderate high-frequency hearing loss, whereas the B elgian and A ustrian families ${ }^{6}$ had stable, more severe, mid-frequency hearing loss. These phenotypic differences correspond to mutations located in two distinct domains which probably play different roles. The finding of additional mutations should allow such a genotype-phenotype relationship to be confirmed.

A $n$ early bilateral vestibular dysfunction suggested in some patients of the French family might be explained by $\alpha$-tectorin role in the vestibular organ: $\alpha$-tectorin is expressed in the 2-day mouse utricular and saccular maculae and thus might be a component of the otolithic membrane or of its accessory membrane. ${ }^{8}$ 
This study provides further evidence that mutations in TECTA cause autosomal dominant hearing impairment and suggests that vicinal cysteines play an important role in tectorial membrane structure.

\section{Acknowledgements}

We thank family members for their cooperation, Drs A Vagne, J M N avette and I Cote-D eplus for patient referral, D r $\mathrm{F}$ Bey-Cabet and $\operatorname{Pr} \mathrm{Y}$ M orel for providing control DNA samples, Pr G L enoir's laboratory for blood sample storage, D r S Fauré and S M archand (Généthon, E vry, France) for technical advice, D r M -C Babron for statistical advice and D r C Petit for helpful discussion. This work was supported by the Centre National de la R echerche Scientifique (U M R 5534), the $U$ niversité Claude Bernard-Lyon 1 , and the Flemish fund for Scientific R esearch.

\section{References}

1 Petit C: G enes responsible for human hereditary deafness: symphony of a thousand. Nat G enet 1996; 14: 385-391.

2 Van Camp G, Willems PJ, Smith RJH: Nonsyndromic hearing impairment: unparalleled heterogeneity. Am J H um G enet 1997; 60: 758-764.

3 Van Camp G, Smith RJH: Hereditary hearing loss homepage 1998 http://dnalab-www.uia.ac.be/dnalab/hhh (September).

4 Verhoeven K, Van Camp G, G ovaerts PJ et al: A gene for autosomal dominant nonsyndromic hearing loss (DFNA 12) maps to chromosome 11q22-24. A m J H um G enet 1997; 60: 1168-1173.
5 Hughes DC, Kevin Legan P, Steel KP, Richardson GP: Mapping of the $\alpha$-tectorin gene (TECTA) to mouse chromosome 9 and human chromosome 11: a candidate for human autosomal dominant nonsyndromic deafness. G enomics 1998; 48: 46-51.

6 Verhoeven $\mathrm{K}$, Van L aer L, K irschhofer $\mathrm{K}$ et al: M utations in the human $\alpha$-tectorin gene cause autosomal dominant non-syndromic hearing impairment. Nat G enet 1998; 19: 60-62.

7 Chaib H, Lina-Granade G, Guilford $P$ et al: A gene responsible for a dominant form of neurosensory nonsyndromic deafness maps to the NSRD 1 recessive deafness gene interval. $\mathrm{H}$ um M ol G enet 1994; 3: 2219-2222.

8 Legan PK, R au A, Keen J N, R ichardson G P: The mouse tectorins. Modular matrix proteins of the inner ear homologous to components of the sperm-egg adhesion system. J B iol Chem 1997; 272: 8791-8801.

9 Edman J C, Ellis L, B lacher RW, Roth RA, R utter WJ : Sequence of protein disulphide isomerase and implications of its relationship to thioredoxin. Nature 1985; 317: 267-270.

10 Mayadas TN, Wagner DD: Vicinal cysteines in the prosequence play a role in von Willebrand factor multimer assembly. Proc Natl A cad Sci USA 1992; 89: 3531-3535.

$11 \mathrm{H}$ ardy D M, G arbers D L: A sperm membrane protein that binds in a species-specific manner to the egg extracellular matrix is homologous to von Willebrand factor. J Biol Chem 1995; 270: 26025-26028.

12 Gum JR, Hicks JW, Toribara NW, Siddiki B, Kim Y S: Molecular cloning of human intestinal mucin (MUC2) CDNA . I dentification of the amino terminus and overall sequence similarity to prepro-von Willebrand factor. J Biol Chem 1994; 269: 2440-2446.

13 Dib C, Fauré S, Fizames $C$ et al: A comprehensive genetic map of the human genome based on 5,264 microsatellites. Nature 1996; 380: 152-154. 